\title{
MISUNDERSTANDINGS AND EXPLICIT/IMPLICIT COMMUNICATION ${ }^{1}$
}

\author{
Francisco Yus
}

\section{Introduction}

Human beings have a wide range of linguistic choices to communicate their thoughts, ranging from the explicit to the implicit. In either case, the utterances chosen are often less fine-grained than the actual thoughts (i.e., assumptions) that the speaker intends to communicate with these utterances, which implies that a certain percentage of success in human conversational interaction is the hearer's in supplying the missing elements in the speaker's utterance.

In this paper I address the interpretive problems that may arise when trying to select the intended explicit/implicit interpretation of an utterance, which basically have to do with (a) deciding whether the intended interpretation is explicit or implicit, and (b) deciding to what extent that interpretation is explicit or implicit (interpretations may be more or less explicit and more or less implicit depending on the contextual information required for their recovery).

The paper begins with a short review of interpretation within relevance theory (Sperber \& Wilson 1986a; henceforth RT) in section one, the cognitive model which will be adopted in this article together with its ad hoc terminology. Section two briefly addresses the fact that speakers have a choice of explicit and implicit means to communicate their thoughts. Section three deals with the notion of continuum and to what extent we can apply this term to explicit/implicit communication (are we dealing with one explicit-implicit continuum, two sub-continua, or two independent continua?). The discussion in this section is important to explain the hearer's interpretive choices which eventually lead to non- or mis-understandings. In section four misunderstandings (as understood in this paper) are defined, and in the next section the scope of analysis in this article is delimited. These five sections make up the theoretical background on which the remaining sections are based. These are devoted to a description and illustration of particular problems that the hearer may face when interpreting explicitly communicated information (section six) or implicitly communicated information (section seven).

\footnotetext{
${ }^{1}$ I would like to thank Victoria Escandell-Vidal and one anonymous referee for comments on a previous draft of this paper. However, I take full personal responsibility for any shortcomings in this resulting article.
} 


\section{Interpretation within relevance theory}

RT (Sperber \& Wilson 1986a) is a cognitive approach to human communication based upon the central claim that human cognition is geared to the addressees' search for relevance in the in-coming (non)-verbal stimuli that they process in the course of a conversational interaction (cf. Blakemore 1992; Sperber \& Wilson 1987; Yus 1997a: 79-136, 1998a, 1998b, for comments and bibliography on the theory). This search for relevance triggers the activation of hypotheses on the explicit or implicit quality of the stimulus which has to be processed, and constrains the eventual choice of a candidate to match the sender's intended interpretation.

According to RT, the traditional code model of communication, which involves only the coding and decoding of utterances, has to be combined with a more down-to-earth inferential model, according to which hearers can only make non-demonstrative hypotheses on the intended interpretation, and only use coded information

as a source of hypothesis and evidence for the second communication process, the inferential one. If comprehension is defined as a process of identifying the speaker's informative intention, linguistic decoding is better seen not as part of comprehension proper, bur rather as providing the main input to the comprehension process (Sperber \& Wilson 1987: 705).

Obviously, this picture of communication is much less automatic. It is, in fact, more risky, and therefore more prone to mismatches between the speaker's intended message and the hearer's chosen interpretation. In other words, it is more open to the interpretive phenomenon of misunderstanding. Wilson (1994: 47) comments upon this idea when she points out that

precisely because utterance interpretation is not a simple matter of decoding, but a fallible process of hypothesis formation and evaluation, there is no guarantee that the interpretation that satisfies the hearer's expectation of relevance will be the correct, i.e. the intended one. Because of mismatches in memory and perceptual systems, the hearer may overlook a hypothesis that the speaker thought would be highly salient, or notice a hypothesis that the speaker had overlooked. Misunderstandings occur. The aim of a theory of communication is to identify the principles underlying the hearer's (fallible) choices.

Within RT, it is claimed that hearers start off their interpretation of a stimulus with an identification of its logical form, which is basically the linguistic raw material decoded by the auditory organs and checked for its grammatical appropriateness. This zero-context logical form is then enriched with contextual information, essential for reference assignment, disambiguation, etc. (cf. Carston 1996). This is a minimally contextualized interpretation of the utterance, which Sperber \& Wilson (1986a) call proposition expressed. Take, for example, Searle's (1978: 210) often-repeated sentence:

The cat is on the mat.

If someone utters (1), once the hearer has identified which specific cat and which specific mat the speaker is talking about (together with locating their spatial orientation), s/he would 
reach the proposition expressed by the utterance. ${ }^{2}$ This proposition can then be embedded in an assumption schema including the speaker's propositional attitude when uttering (1). When the speaker makes mutually manifest that s/he intends to communicate this proposition expressed, the proposition is then called explicature. Therefore, the proposition expressed should not be equated to the explicature of the utterance: "the proposition expressed may or may not be actually (ostensively) communicated; that is, it may or may not be an instance of $P$ in the schema 'the speaker makes mutually manifest her intention to make manifest to the addressee that $P$ '. The proposition expressed by a metaphorical, ironical or some other kind of non-literal utterance is not communicated in this sense, but rather serves as an effective and efficient means of giving the hearer access to those assumptions which are communicated. In other words, the proposition expressed may or may not be an 'explicature'" (Carston 1998b: 471).

On the other hand, if the information provided by this proposition is not found informationally satisfactory (it does not fit the principle of relevance ${ }^{3}$ in Sperber \& Wilson's 1986a terms), then the hearer will conclude that its (explicit) information does not match the speaker's intended interpretation. ${ }^{4}$ The hearer will then look for (and test) extra contextual assumptions which will (or won't in the case of misunderstandings) lead to the now turned implicit - information which the speaker supposedly intended to communicate. For example, if the cat in example (1) above usually sits on the mat whenever it is hungry, the (implicitly conveyed) interpretation that the cat is hungry (2) reaches beyond (is not a

${ }^{2}$ One of the main differences between Grice's what is said and this notion of proposition expressed is that the recovery of the latter requires much more contextual input than Grice pictured. On this issue, see Carston (1996), Bertuccelli Papi (1999: 58), Blakemore (1989: 31), Récanati (1989; 1993), Bach (1994a; 1994b), and Gibbs \& Moise (1997: 52-53), among others. On the other hand, several principles have been proposed to account for what amount of meaning is actually covered by the proposition expressed (and what amount belongs to the implicature). See, for instance, the availability principle (Récanati 1989), the functional independence criterion (Carston 1988), or the minimal truth-evaluability principle (Récanati 1993: 242).

${ }^{3}$ According to Sperber \& Wilson (1986a: 50), "humans automatically turn their attention to what seems most relevant to them... An act of ostension carries a guarantee of relevance, and this fact - which [they] call the principle of relevance- makes manifest the intention behind ostension". S\&W define their principle of relevance as follows: "each act of ostensive communication carries the presumption of its own optimal relevance." For the principle to be satisfied, the following premises have to be satisfied: (a) The assumptions $\{I\}$ that the sender intends to make manifest to the addressee are sufficiently relevant to be worth the audience's processing of the ostensive stimulus. (b) The ostensive stimulus is the most relevant that the sender can use to communicate $\{I\}$.

In the Postface to the second edition of Relevance, Sperber \& Wilson (1995: 260ff) acknowledge that people tend to use the notion of principle of relevance both in a broad cognitive sense ("human cognition tends to be geared to the maximisation of relevance"), and in a more restrictive communicative sense ("every act of ostensive communication communicates a presumption of its own optimal relevance"), which leads to a dual proposal of principles: a "first cognitive principle" and a "second communicative principle." The latter is the one the book by Sperber \& Wilson is mainly about.

${ }^{4}$ Since my definition of explicitness involves the rejection of all literalness which is not linked to contextualization, regardless of how minimal this cognitive operation is, theories such as the extensionalist theory (see Gibbs 1994: 30) or Katz's compositional view of meaning in a zero or null context (that is, "where any sentence-meaning is derived from a complex synthesis of meanings of its composite words", see Toolan 1991: 334) should be rejected. 
development of) the logical form yielding the proposition expressed by the utterance, and enters the realm of the implicature. In this particular case, the hearer will probably search for an implicit interpretation, once s/he finds the explicit information about where the cat is totally irrelevant. Consequently, the interpretation (2) of utterance (1), and other possible implicit interpretations such as (3), would be implicatures of (1):

The cat is hungry!

Feed the cat!

This line of argumentation suggests that speakers have a choice of different utterances to communicate their thoughts. Of course, we should be careful here not to bestow speakers with so much rationality as to be always aware of the range of all the possible utterances available to communicate their thoughts in a specific conversational context, and pick up precisely the one that best fits their communicative intentions. As Escandell-Vidal (personal communication) correctly points out, it often feels as if the speaker has different alternative utterances to choose from when attempting to communicate thoughts at a particular stage of the conversation, but this is easier to analyse from the addressee's (or analyst's) point of view than it is from the speaker's. Often in on-going conversations speakers simply come up with one utterance which aims at fitting their communicative intentions faithfully and, in cases of misrepresentation, may not succeed in communicating the intended interpretation (unlike a current version of a strong 'effability principle', which claims that any thought/proposition can be encoded by some sentence in any natural language, cf. Carston 1998a: 67ff). In other words, there is indeed a range of possible utterances, but this need not imply a constant awareness, on the speaker's side, of having chosen one utterance (i.e. the best available) out of this range, let alone awareness of the alternative utterances that could have been used instead of the one selected.

The picture outlined so far indicates that the same 'proposition expressed' can be used to communicate explicit and implicit information, whose recovery is always guided by expectations of relevance. Interpretations can thus be arranged on a scale of explicitnessimplicitness and, due to the higher context-dependence of implicitly conveyed information, the more implicit the intended interpretation is (i.e., the greater the number of contextual assumptions required for the listener to interpret the message) the more likely it is that the interpretive process will end up in some kind of speaker-hearer mismatch. In other words, the more hearer-dependent and the less speaker-controlled interpretation is, the greater the risk of eventual misunderstanding. Indeed, the speaker is supposed to take account of the addressee's immediately accessible assumptions and the inferences he can readily draw when interpreting the utterance, but the speaker can make wrong predictions about the addressee's ability to recover this information (Carston 1998a: 66).

The next section will further illustrate the speaker's choice of interpretations between the explicit and the implicit.

\section{A range of possible utterances in an explicit/implicit continuum}

The RT-based picture of interpretation outlined above implies, as we have just seen, that information can be communicated explicitly or implicitly, and that the more contextual 
assumptions which the hearer has to extract from contextual sources, the more the speaker has to rely on the interlocutor for an optimal interpretive outcome. Blass (1990: 50-52) provides a good example (slightly adapted here) of how a series of answers to question (4a) range from the explicit answer (4b, my addition), to the increasingly implicit answers (4ce), each of them demanding more and more contextual assumptions to be provided by the interlocutor:

(4) (a) Do I look strange in my cover cloth?

(b) Explicit answer: No, you don't look strange in your cover cloth.

(c) Implicit answer (1): Everybody wears them around here. [contextual assumption needed: (1) people do not look odd if they wear what everybody is wearing]

(d) (More) implicit answer (2): We are in Africa.

[contextual assumptions needed: (1) many women in Africa wear cover cloths; (2) people do not look odd if they wear what everybody is wearing].

(e) (Even more) implicit answer (3): We are in a hot continent.

[contextual assumptions needed: (1) Africa is the continent that she is talking about; (2) many women in Africa wear cover cloths; (3) people do not look odd if they wear what everybody is wearing].

Examples such as (4) above indicate that not only is there an explicit/implicit interpretive choice for an utterance, but there are also degrees of explicitness and degrees of implicitness (Blakemore 1989: 31; Carston 1988: 167). An example of the latter can be found in (4c-e) above. The former is exemplified in (5) below (Carston 1999: 113), in which roughly the same proposition is communicated (explicitly), but explicitness decreases as we move down in the choice of utterances, and thus the speaker's reliance on the hearer's ability to supply contextual information increases accordingly:

(a) Mary Jones put the book by Chomsky on the table in the downstairs sitting-room.

(b) Mary put the book on the table.

(c) She put it there.

(d) On the table.

In this sense, one may wonder why people engage in implicit communication at all, if implicit communication is more demanding (on the hearer side) than explicit communication, and more risky due to the aforementioned hearer-dependence. Maybe speakers would avoid a lot of risks if they just communicated their thoughts in an explicit, straightforward way... Needless to say, on many occasions one would not be able to provide the same quality and quantity of information unless one chose an implicit utterance. If someone asks "Would you like to go to the cinema?" and the hearer indirectly answers "I'm tired", s/he is not only saying that s/he does not want to go to the cinema, but also providing a reason why, an economical way of communicating several assumptions simultaneously. Besides, implicit communication is often used in order to make the interpretation the hearer's sole responsibility, as in most polite indirect requests which mitigate face-threatening acts (Holtgraves 1998). So, we conclude that implicit messages 
are not an exception to a general explicit-only rule for human communication but, rather, one of its inherent qualities.

An example of how implicit communication may be used to hide covert intentions (in the form of weak implicatures) and leave the extraction of these meanings entirely to the interlocutor can be found in the film In your dreams (O. Parker, BBC2, 14 December 1997). A young man and a young girl are in a park and they walk past a bench. The boy wants to sit down in order to start a sexual - kissing - strategy, but he is afraid to let her know in a straightforward manner for fear of giving himself away. If he says (6a), he will surely activate unwanted connotations in the woman's interpretation of the stimulus. Therefore, he chooses the utterance (6b) instead, in order to communicate his intentions implicitly, and the woman finally takes the responsibility for extracting the intended information:

(a) A. Do you want to sit down on the bench with me?

(b) A. Oh! look! There's a bench!

B. You wanna sit down? Is that what you're saying?

A. Is that $\mathrm{OK}$ with you?

B. Yeah... why not?

To sum up, implicit communication may be more demanding, but it is far from unusual, and satisfies a high number of communicative purposes in ordinary conversations, ranging from the communication of information connoted with contextual implications, to making information mutually manifest, or to the performance of conversational strategies such as face-saving politeness.

\section{One continuum or two continua?}

So far, we have reached the conclusion that speakers have a choice (more theoretical than actually explicitly entertained on many occasions) of utterances ranging from the most explicit and speaker-controlled to the most implicit and hearer-demanding. Does this choice exist in a smooth explicit-implicit continuum? In Yus (1997b, Yus 1999) it was argued that instead of one continuum between two poles (one explicit and one implicit), the speaker's choice is, rather, between two sub-continua, one explicit and one implicit, and each of them with its own explicit-implicit gradation. In this paper, this proposal is further developed into a theory of (independent) continua: e-continuum for explicit communication, and $i$-continuum for implicit communication. The term sub-continuum (explicit or implicit), as used in previous research, seemed to imply that these are sub-groups inside a general explicit-implicit continuum. However, since explicit and implicit interpretations of an utterance do not overlap (cf. Carston's 1988 functional independence criterion), they must be treated as independent continua. ${ }^{5}$

The new terminology retains the previous claim that each continuum has its own

\footnotetext{
${ }^{5}$ Other terminological proposals have been suggested to be added to the explicit/implicit duality, for example Bach's (1994a; 1994b) context-bound-but-still-explicit impliciture (see Vicente 1998 for discussion), but we will retain the two-fold basic quality of stimuli between the explicit and the implicit.
} 
explicit-implicit gradation, which helps us to understand the fact that several pragmatic processes are required in order to reach a proposition which can then be communicated as an explicature or be used as premise for the derivation of implicatures: Reference assignment, disambiguation, enrichment, and loosening (see Carston 1996; Bertuccelli Papi 1999; Récanati 1989, 1993, 1994; Carston 1999; Gibbs \& Moise 1997), and the amount of contextual information required for the development of the logical form or the recovery of implicatures varies depending on how explicitly or implicitly the intended interpretation is communicated.

Similarly, the fact that there is an implicit side in the e-continuum makes it possible to explain examples such as the (overused) question Can you pass the salt? (more on this below). In this e-continuum we would fit not only straightforward, factual information but also (more implicative, but still explicit) set-phrases like politeness formulas and certain non-implicative metaphors (fossilized metaphors turned explicit due to a process of conventionalization), among other possibilities. Besides, Bach (1998) analyzes a process of standardization, according to which an utterance goes beyond literal meaning and yet can be explained without special conventions. This process can clearly be fitted into this two-continua model, now pictured as belonging to the implicit end of the e-continuum. Bach suggests several linguistic areas which are prone to standardization, including (1) performative utterances, (2) standardized nonliterality, (3) what he calls "conversational implic-i-ture", as opposed to Grice's implic-a-ture (see note 5), and (4) various cases of singular reference, including referential uses of definite descriptions.

The fact that there are degrees of explicitness (ranging from the most explicit to the more-implicit-but-still-explicit information) inside this e-continuum can be illustrated with Sperber \& Wilson's (1986b) notion of loose talk. Often, speakers do not communicate the exact information that they know (and are indeed able to communicate) because being so exact would make the interlocutor extract unintended and unnecessary implications (cf. Franken 1997). In Carston's (1996: 66) words:

in some instances a speaker chooses to produce an utterance which is a less-than-literal (that is, loose) interpretation of the thought she intends to communicate. This will arise when she judges that communication of her thought is facilitated by such non-literal utterance in that it makes the thought more accessible to the hearer than a literal one would

For example:

(7) (a) I live three kilometres from Alicante.

(b) I live two thousand, nine hundred and fifty-three metres from Alicante.

As the reader will notice, (7b) is so exact that it simply is not relevant for the hearer in normal circumstances, and the speaker is risking the breakdown of successful communication by demanding extra effort in exchange for very straightforward factual information. Besides, (7b) is more literal than (7a), but we could still state that both (7a) and $(7 b)$ are explicitly conveyed information. Consequently, it can be stated that there is not one continuum ranging from very explicit information to the most implicit information that can be communicated in a specific speech situation. Instead, two continua are proposed, one on the explicit side (e-continuum) and one on the implicit side (i-continuum), and each of them with different degrees of indirectness. 
The key word for the shift from the e-continuum to the $i$-continuum is whether or not the interpretation is a development of the logical form of the utterance or not. Sperber \& Wilson (1986a) define explicatures as "contextual information is used to enrich the logical form into a propositional form (which then is optimally embedded into an assumption schema typically expressing an attitude to it)". Unlike explicatures, implicatures such as (2-3) above are totally context-dependent and not straightforwardly deducible from the utterance, that is, they are not developments of the logical form, but constructed according to a combination of contextual information and the proposition expressed by the utterance.

In theory, the boundary between explicatures and implicatures should be clear-cut: speakers communicate either explicatures or implicatures, but in reality there is a lot of scholarly discussion on what portion of the (intended) meaning of the utterance is actually covered by the implicature and what belongs to the explicit information provided by the utterance. In Gibbs \& Moise (1997) we find the following example:

(a) Robert broke a finger last night.

[contextual assumptions: The speaker is a football player in the same team as Robert. The speaker is responding to a question about Robert's whereabouts, asked by the team coach on the day of a big game].

(b) Robert broke a finger, either his own or someone else's, on the night prior to uttering (8a).

(c) Robert broke his own finger on the night prior to uttering (8a).

(d) Robert can't play the game today.

According to the standard Gricean picture, (8b) would be 'what is literally said'; (8c) would be a 'generalized conversational implicature'; and (8d) would be a 'particularized conversational implicature'. For Récanati (1989), (8b) would be a 'minimal proposition' not consciously available to people; (8c) would be 'what is said' (an enriched explicature consciously available to people); and (8d) would be an implicature. Within RT, (8b) would be considered (r la Grice) as the proposition strictly and literally expressed by (8a), "the minimal proposition that can be constructed from the semantic representation of the utterance, something which departs as little as possible from encoded content and yet which has a determinate truth-condition" (Carston 1996: 85). RT is more interested in (8c), the proposition expressed by (8a), a proposition pragmatically constructed out of the concepts encoded in the logical form of the utterance and communicated explicitly as an explicature, or serving as one of the elements needed to derive a context-bound implicature (8d).

In a previous draft of this paper, I also claimed that one of the keys to the shift from the $e$-continuum to the $i$-continuum was the speaker's "awareness" (to use the term with its weakest connotations) that $\mathrm{s} / \mathrm{he}$ is demanding from the interlocutor the use of contextual information which is not part of the development of the logical form yielding the 'proposition expressed'. Although I agree with an anonymous referee that this is too strong a claim (the relevance-seeking processing of utterances is biologically rooted and arises spontaneously), I would still underline the fact that people often do have intuitions about the explicit-implicit quality of the intended interpretation of utterances (in a folk-linguistic 
way). Even within scientific pragmatic research we can find references to these intuitions, as in Récanati's (1989) availability principle ("in deciding whether a pragmatically determined aspect of utterance meaning is part of what is said, that is, in making a decision concerning what is said, we should always try to preserve our pre-theoretic intuitions on the matter").

Furthermore, Gibbs \& Moise (1997) carried out several experiments demonstrating that people intuitively recognize a distinction between what is said and what speakers implicate with an utterance in particular contexts (see Nicolle \& Clark 1999 for a reply, and Gibbs 1999 for a counter-reply). For example, an experiment showed that in situation (9a), people intuitively distinguish between the explicit reading (9b) of Fred's utterance, and a possible indirect meaning such as $(9 \mathrm{c})$

(9) (a) Bill wanted to date his co-worker Jane. But Bill really didn't know much about her. Being a bit shy, he first talked to another person, Fred. Fred knew Jane; fairly well. Bill wondered if Jane was single. Fred replied, Jane has three children.

(b) Jane has exactly three children, but no more than three.

(c) Jane is married.

Of course, relying only on intuitions is not scientifically advisable. But its role in deciding what is explicitly or implicitly communicated should not be totally dismissed. Récanati's (1993: 254, note 12) comments on this issue are particularly illustrative:

\begin{abstract}
I agree that scientific theorizing is to be freed from, rather than impeded by, intuitions and common sense, which provide only a starting point... Still, I believe there was something to worry about when the theory of implicatures was extended to examples which we would not ordinarily consider as cases of implied meaning. ${ }^{6}$ This does not mean that I reject the 'scientific' attitude towards common sense. We may at the same time accept this attitude and recognize that human cognition is a very special field: in this field, our intuitions are not just a first shot at a theory... but also part of what the theory is about, and as such they cannot be neglected.
\end{abstract}

Returning to what is covered by the continua, in my opinion, following the relevance-theoretic claim that reaching the explicit information of an utterance (Sperber \& Wilson's proposition expressed; Récanati's what is said) also requires several pragmatic processes of contextualization, it can be stated that the e-continuum covers much more pragmatic information than Grice pictured. For instance, the problematic Can you pass the salt? (10b) would now be explained as an explicit request (and not a factual ability-related question which is treated as if it were a request, cf. Bertolet 1994: 336), but more literal than, for example, (10a); and less literal than (10c), which would be the most explicit of the three. And they all (10a-c) would still be placed inside the limits of the e-continuum:

(a) I wonder if you could possibly be so kind as to pass the salt, please?

${ }^{6}$ For example, in the classical Gricean analysis, (9b) would be treated as a conversational implicature that combines with the proposition expressed (i.e., that Jane has at least three children, but may have more). However, as Récanati claims quite correctly, no speaker would admit that he intended to communicate that Jane has at least three children with his utterance. 
(b) Can you pass the salt?

(c) Give/pass/hand me the salt, please.

Therefore, even though the speaker may be aware that s/he is using a polite formula for this request, I do not think that the speaker is intentionally demanding extra cognitive effort from the interlocutor (cf. Gibbs 1979; 1984). In other words, the speaker's intended interpretation is still rather explicit: a request, even if the speaker uses a polite formula to communicate it. It is clear that the speaker is not interested in the hearer's competence at salt-passing, and is merely asking for the salt by means of a shared convention: a (culturebound) fixed polite formula (cf. Clark 1979). I therefore take the conventional approach to indirect requests and reject the natural approach under which the speaker makes a request disguised as a literal yes/no question. But I also reject the assumed underlying ambiguity, implicit in the conventional approach, between the literal meaning of a yes/no question and the literal meaning of a request (Groefsema 1992). Rather, I picture the hearer as assuming the conventionality of a yes/no question for the request and this convention, being highly salient, leaves the alternative 'ability-reading' of the question in the dark, as it were. This is in tune with the so-called standardization thesis:

the requestive use of [can you...?] short-circuits the SAS [speech act schema], the hearer identifying the speaker's requestive illocutionary intent without having to identify the literal intent of questioning. He does this by relying on the precedent for the form's being used requestively. This precedent and the hearer's unthinking reliance on it depend on the form's being specifiable in some syntactically determinate way, and it must be such that the connection between the literal force/content and the indirect force/content is simple and systematic (Bach \& Harnish 1979: 706).

a form of words is standardized for a certain use if this use, though regularized, goes beyond literal meaning and yet can be explained without special conventions... there is a certain core of linguistic meaning attributable on compositional grounds but a common use that cannot be explained in terms of linguistic meaning alone. The familiarity of the form of words, together with a familiar inference route from their literal meaning to what the speaker could plausibly be taken to mean using them, streamlines the process of identifying what the speaker is conveying (Bach 1998: 713).

In any case, this statement does not reject the possibility that, given certain contextual attributes, the 'ability-reading' of can you...? will be more salient and hence be considered more relevant in the course of the conversation (cf. Clark 1979; Groefsema 1992; Vicente 1996; Yus 1997e: 248-252). This would be the case of the question can you...? (11b) in the situation (11a):

[A and $B$ are checking a house that they are interested in buying. A suddenly sees $B$ inspecting one of the windows].

(b) A. Can you open the windows?

B. Yes, they all seem to be in fine condition.

On the other hand, if the speaker avoids fixed polite formulas identifiable in their (indirect) explicit quality, a shift to the $i$-continuum would take place. For instance, there would be a world of a difference if the speaker said (12) instead of (10b) to ask for the salt:

Are you sitting near the salt? 
Since there is a great deal of (implicit) contextual information needed to reach the intended interpretation of the request (and not deducible from the logical form of the utterance), (12) would definitely belong to the $i$-continuum. ${ }^{7}$ Notice that (12) is viewed here as an utterance that the speaker says with the overt intention of forcing the interlocutor into looking for an implicit request-meaning (once the proposition expressed by the utterance - the physical location of the interlocutor - has been found to be totally irrelevant), a search which is activated precisely because (12) strikes the hearer as unusual, that is, as not fitting ordinary formulas used for requesting (not even those conventional utterances that can be placed at the implicit end of the e-continuum). Therefore, I do not agree with Escandell-Vidal (personal communication) when she points out that, since (13b) below is not considered more demanding than (13a) in normal conversational contexts (her suggested examples), the same should be said about (12) and (10b):

(a) Can you pass the scissors?

(b) Have you got a pair of scissors handy?

I would say that (13b) is significantly different from (12) in the degree of conventionality that it displays. Unlike (12), which is a novel, unusual way to ask for the salt, and bound to strike the hearer and lead him to a search for a more relevant implicit interpretation, (13b) is, no doubt, more implicit than (13a), but it still activates the "fixed formula for request" conventionality that was mentioned above as belonging to the implicit end of the e-continuum. (13b) is, particularly, a case of transfer from the $i$-continuum to the e-continuum. There are several reasons why a certain utterance may be transferred to the other continuum, one of them being the fact that certain expressions tend to be used systematically to achieve specific communicative purposes and eventually end up becoming attached to these purposes in the range of communicative choices used by the community of speakers. Being fixed in their shared use, expressions such as (10b) and (13b) often lose much of their implicative potential and cross the boundary into the implicit side of the e-continuum (together with a thorough invalidation of their covert explicitness, that is, the ability meaning in (10b) and possession meaning in (13b)), and speakers finally use them without realising their inherent ambiguity. Unlike (10b) and (13b), example (12) and also other examples such as (4c-e) above indicate that there are other, more explicit ways of communicating the information, and the speaker may be aware of the extra processing effort that he is demanding from his interlocutor (of course, the speaker must also be aware of the extra offset of cognitive effects provided by implicit means). This illustration is subordinated to the fact that the so-called permeability of the boundary between the e-continuum and the $i$-continuum is unstable. There is a constant transfer of information between the two continua, and it is possible even for utterances such as (12) to become fixed formulas and end up being deprived of their implicit connotations.

Metaphors and certain figurative language events can also be explained using this

${ }^{7}$ In cases like these, I assume that the speaker intends a specific interpretation despite resorting to an indirect request. Although indirect utterances (e.g. indirect speech acts) may be open to multiple interpretations, especially when weak implicatures or poetic effects are encouraged by the indirect quality of the utterance (Carston 1988: 178, note 5), it is not always the case that "they are deliberately open to more than one understanding simultaneously", as Weigand (1999: 765) claims (my emphasis). 
terminology. Often, novel metaphors are finally incorporated into the normal, ordinary (i.e. explicit) use of language (together with many other metaphorical mappings which show that our mind is organised figuratively), and become fossil metaphors belonging to the e-continuum. On many of these occasions, the speaker is likely not to be aware of conveying a metaphorical message and will regard it as explicitly communicated information (for example, in utterances such as the prices have gone up).

Transfers may also occur in the opposite direction: from the e-continuum to the $i$-continuum. In this case, the implicative reading of the utterance is finally more salient than the initial explicit reading, and this implicit meaning is finally used consistently by a community of users, depriving the utterance of its initial explicit sense.

As a consequence, we can see how the two continua proposed show a great deal of permeability with recurrent transfers between continua according to the form and use that utterances acquire and their unstable explicit/implicit interpretations, under the pressure of social contexts and constraints in particular speech situations (among many other possible constraints) imposing specific readings upon certain linguistic forms. This fact may well be a source of further difficulty for hearers when interpreting utterances explicitly or implicitly.

For example, in the film In your dreams (O. Parker, BBC2, 14 December 1997) we can feel the tension between the explicit and implicit interpretations of the same utterance and the pressure imposed upon these readings by the social context. The film is specifically about date-rape, and one of the key scenes is when the male protagonist gets the girl to ask him up for coffee. Traditionally, "inviting someone for coffee" may have an explicit reading of "inviting someone to have a cup of coffee" and a subtler, implicative reading: "inviting someone for sex". The implicit reading has been exploited so much in films and other media discourses that it now seems as if one cannot use the utterance to convey any alternative meaning but the sexually connoted one (an example of transfer from the $e$-continuum to the $i$-continuum due to social pressure). From the conversation between the male protagonist (A) and his female friend (B) which is quoted in (14) the spectators of the film will conclude that the girl is well aware of the two alternative meanings (explicit/implicit) and of the strong bias towards the implicative meaning attached to "having coffee" over the (nowadays almost nonexistent) explicit meaning. Therefore, she tries her best to make it clear that the utterance has to be understood in its explicit meaning:

(14) A. Any danger of a coffee? Go on!

B. Just coffee, eh?

A. Oh yeah, just coffee.

B. Nothing else?

A. Well, a bit of milk would be good...

B. No...

A. ...and some sugar, if you've got any.

B. Jimmy!

A. But if not, you know..., that's fine.

B. Yeah, I've got some sugar.

A. Ideal!

However, when facing trial for date-rape, the male protagonist clings to the fact that the 
implicative meaning of "having coffee" is nowadays seen as the only possible interpretation of the utterance, thus opening up the possibility that his victim actually invited him up for sex:

(15) When we went up... I'm not gonna lie. We went up for coffee.... But it's a code! It's accepted! We all know... we all know what it means!

T. Piper (in Brooks 1999) corroborates this implicit-only reading when he states that

(16) The question of going back for coffee is established shorthand. "Everyone knows what it means. A bloke who asks is a bit of a chancer - if she says no, he won't be slighted, he'd even expect a negative answer. It's part of some stupid ritual."

Another example of this tension in the converging explicit and implicit meanings of utterances can be found in the use of idioms in advertising. Idioms are typically ascribable to the $i$-continuum, since they require extra contextual information from the hearer in order to reach the (unitary) meaning of the idiomatic phrase beyond the explicit meaning of its composite words (normally, the two meanings share little or no resemblance). However, advertisers usually force the recipients of the ad to compute the two possible readings of the phrase (explicit/implicit) in order to draw their attention to the word play (and eventually to the product advertised). In other words, advertisers provoke a transfer from the assumed implicit meaning of the idiom to a parallel processing of its explicit meaning. This effect is usually achieved by means of a picture accompanying the idiom on which the ad is based, or by means of some textual information preceding or following the idiom, which activates an explicit interpretation of the phrase containing it. Some examples can be found in Díez Arroyo (1997):

(17) Ad: "Where we are, you won't miss the boat".

Source: The Economist, 3 September 1994.

Idiom: "Miss the boat" (= fail to take advantage of a chance).

Transfer-to-explicit trigger: Picture of several boats.

(18) Ad: "Our financial skills helped one gold mining company find the light at the end of the tunnel.

Source: The Economist, 6 August 1994.

Idiom: "See the light at the end of the tunnel" (= metaphor for helping the company sort out problems).

Transfer-to-explicit trigger: Previous text, specifically "gold mining".

As a summary, in this section two continua have been proposed, each of them with its own scale ranging from the explicit to the implicit. The boundary between these continua is, in theory, clear-cut depending on how much the interpretation is (explicature) or not (implicature) a development of the logical form of the utterance. However, this boundary is subject to constant permeability under certain social conditions of use. Transfers between the two continua are frequent, opening up new threats for the hearer's optimal interpretation of utterances. 


\section{A two-fold picture of misunderstandings}

For the purposes of the present study, misunderstandings will be defined as follows:

(a) When the addressee picks up an interpretation $X_{b}$, among a choice of interpretations $\mathrm{X}_{1} \ldots \mathrm{X}_{\mathrm{n}}$ in a certain context $C$, which is different from the interpretation $\mathrm{X}_{\mathrm{a}}$ that the addresser wanted to communicate with a verbal or nonverbal stimulus.

(b) When a person interprets incorrectly the information which, without a prior communicative intention, reaches that person from the surrounding world. In other words, a wrong interpretation of exuded information.

Two theoretical assumptions underlie this two-fold picture of misunderstandings:

(1) In reality, there is often no such thing as an exact match between the addresser's intended interpretation and the addressee's chosen one. As Linell (1995: 181) points out, understanding is necessarily partial and fragmentary, and speakers leave utterances indeterminate on many points, since they cannot or do not want to commit themselves to complete specification (see also Weigand 1999: 769). It should be noted that "communication rests on mutual trust between responsible individuals, treated by each other as capable of using reasonably well linguistic and non-linguistic means to convey and recognize communicative intentions. We are, of course, speaking of presumptions, which are fallible - which is why misunderstanding actually does occur" (Dascal 1999: 757).

(2) The kind of communication in which we are interested here is the speaker's intentionally conveyed verbal stimulus (cf. Gibbs 1998). Indeed, "normally, speech is used to convey one pragmatic interpretation, and success in communication is measured by the addressee's ability to reach that interpretation" (Dascal \& Berenstein 1987: 140). However, we can also misunderstand unintentionally conveyed exuded information, that is, information which reaches our mental processing devices without the mediation of a sender's prior communicative intention. RT is only concerned with ostensive behaviour (under which the informative intention is grasped by means of a parallel recognition of the sender's - intentionally conveyed - communicative intention) and reject the analysis of information accessed unintentionally. In reality, human beings devote a great deal of their cognitive effort both to making hypotheses on the right interpretation of in-coming information from the surrounding world, and also to making this newly processed information fit schematic, stereotypical information already stored on their minds. As example (19) suggests, processing people's exuded behaviour can also result in misunderstanding ("Happy Larry", Smut 26 [1-1993], p. 37):

(19) [a character watching a neighbour giving something to the pigeons]

A. What are you doing?

B. What does it look like I am doing?

A. You are a big softy at heart, "feeding the birds"!

B. I'm not feeding them, I'm poisoning the little bastards! That'll teach them to wake me up at 4 o'clock in the morning! 
Clark's (1996: 192) words are also illustrative here:

\begin{abstract}
People try to make sense of the world around them. When they see things happen, they try to interpret them, to construe them as one thing and not another. Many things are easy to construe. I see a fish, and I construe it as a fish, as a trout, or as food for a grizzly bear. Social events aren't always so easy. I see a strange man walking towards me. Is he approaching me by accident, or by design? Does he want to ask me directions, rob me, or what? My construal will determine what I do next.
\end{abstract}

\title{
5. Scope of analysis
}

The present study will centre upon intentionally conveyed verbal utterances which are placed somewhere in the e-continuum or the i-continuum (see Dascal \& Gruengard 1981; Yus 1997c, 1998c, 1999; Bazzanella \& Damiano 1999: 829, for further analysis comprising intentionality and nonverbal communication). It will also be assumed that the speaker does not want to be misunderstood. This leaves out instances in which the speaker does want the hearer to choose an interpretation which is eventually incorrect (Weigand 1999: 764). The most pervasive source of this kind of discursive strategy can be found in humorous discourse, in which the addresser's overt intention is to make one interpretation highly salient and accessible (especially in so-called garden-path jokes). This interpretation is later invalidated and when the addresser's covert intention unfolds, it turns out that s/he really intends to communicate a less likely (but still possible) interpretation (cf. Yus 1997d, 1997e, 1998d for comments on an possible application of RT to this gradation of interpretations). Yamaguchi (1988) illustrates this choice of interpretations with the following joke:

(20) A pair of suburban couples who had known each other for quite some time talked it over and decided to do a little conjugal swapping. The trade was made the following evening, and the newly arranged couples retired to their respective houses. After about an hour of bedroom bliss, one of the wives propped herself up, looked at her new partner and said: "Well, I wonder how the boys are getting along".

Here the humorist knows or assumes that the most salient and accessible interpretation is "heterosexual swapping", but the eventually correct interpretation turns out to be the (less likely) "homosexual swapping". I would even claim that, since in examples like these the addressee picks up precisely the (eventually wrong) interpretation that the humorist wanted $\mathrm{him} / \mathrm{her}$ to choose, the interpretive outcome may actually be labelled effective communication.

Second, the analysis in this study will focus on the hearer's inability to grasp the intended interpretation. But it is assumed, in an intersubjective picture of human interaction, that often misunderstandings are a joint responsibility between the hearer's non- or mis-understanding and the speaker's misrepresentation (Linell 1995: 185). This shared responsibility of communication has led to a distinction between misunderstandings at the I-level, and misunderstandings at the We-level (Weizman \& Blum-Kulka 1992; Weizman 1999). The former refers to an individual speaker's meanings, whereas the latter 
has to do with collective, mutually shared direction of the exchange. Actually, often interlocutors follow different conversational paths without noticing that a misunderstanding has occurred. In these cases, there is a misalignment between the interpretations of the dialogue given by the speaker and the interlocutor. The distance between participants' interpretations of the conversation will normally lead, later on, to one of them being unable to integrate subsequent turns in a coherent manner. Since they have different contexts at their disposal for the task of interpretation, they lack the basic condition for reconstructing, at any subsequent turn, the other's conversational path. At the same time, unless they discover the failure in mutuality, they will continue to make their contributions by referring to different contexts (Bazzanella \& Damiano 1999a; 1999b: 821).

Third, in this analysis it is supposed that hearers try their best to grasp the speakers' intended interpretation but fail. Therefore we leave aside cases in which the hearer pretends not to have heard (Grimshaw's 1980 spurious non-hearing) or in which the hearer does understand but acts as if s/he did not (Grimshaw's 1980 deliberate misunderstanding).

Fourth, in this article possible sources of misunderstanding will be suggested, but the actual processes of repair that interlocutors may carry out in order to return to mutual understanding will not be analyzed (cf. Schegloff 1992; Bazzanella \& Damiano 1999: 831).

\section{Communication problems in the e-continuum}

After this theoretical background, we can now analyse misunderstandings in the two continua. Let us imagine, first, that a speaker wants to communicate the information contained in the proposition expressed by the utterance, that is, that a speaker wants to communicate the explicature of the utterance. What problems for optimal understanding can arise? As illustrated in figure 1, there are four main threats to optimal interpretation of utterances in the e-continuum. These are outlined below. Most of the examples provided (also in section seven below) have been taken from conversations in films.

1. Unlike cases 2-4 below, in which the hearer does build up a hypothetical interpretation of the speaker's utterance which turns out to be different from the intended one, in case 1 the hearer is unable to come up with any plausible interpretation of the speaker's utterance. This can occur in two apparently unrelated communicative situations: (a) when due to noise in the channel of communication, the speaker's bad pronunciation or strong accent, or poor command of the language on either of the interlocutors' sides, the message does not reach the addressee in an optimal way, thus leading to nonunderstanding, rather than misunderstanding (Humphreys-Jones 1986: 109). Here, instances which fit Grimshaw's (1980) nonhearing and mishearing may be included. Contrary to Weigand (1999: 774-775), who claims that "even in cases where we cannot identify the phonological sequence we nevertheless try to understand and may thus come to a false identification", in my opinion there are cases in which the human processing device is utterly unable to ascribe a meaningful sense to the string of words which the speaker has uttered.

(b) Besides, lack of required encyclopaedic knowledge often makes it imposible to access any plausible interpretation of the utterance. This is the case of very specialized jargons or specific metalanguages. One specific area which has been studied in this respect is the misunderstandings arising in institutional settings such as clinical interviews between 
doctors/counsellors and their patients (cf. Grossen 1996; Grossen \& Apothéloz 1996; Maynard 1991; Salazar Orvig 1995; West 1985; Cameron \& Williams 1997, among others). Therefore, this second type of non-understanding can be considered at two basic levels: one horizontal, typically arising in cross-cultural communication and also in different linguistic varieties within the same culture; and one vertical, e.g. in conversations between experts and laymen, typically in institutional settings (Weigand 1991: 764). However, both types would fit Schegloff's (1987) externally caused trouble (trouble caused by social-cultural-linguistic differences between interlocutors), as opposed to internally caused trouble (arising in same-level, harmonious background of interlocutors).

2. A second source of misunderstanding in the e-continuum is what I label puzzled understanding. In this case, the hearer does identify the speaker's intention to communicate (as an explicature) the information expressed by the proposition of the utterance (in other words, doesn't look for extra contextual assumptions in order to build up an implicature of the utterance). However, after enriching the logical form to yield the proposition expressed, its eventual embedding in an assumption schema incorporating the speaker's attitude

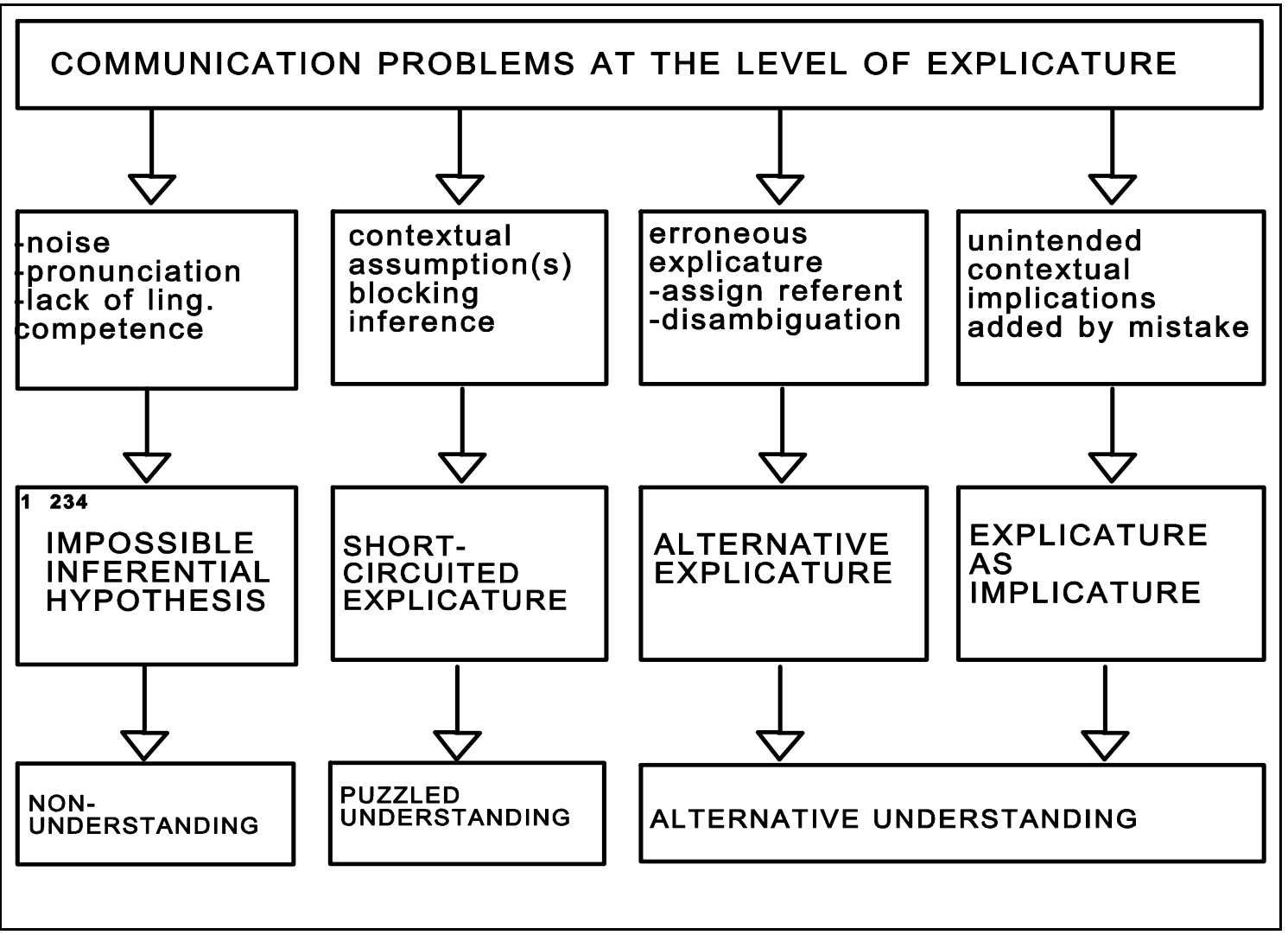

Figure 1.

(towards communicating it as an explicature) is somehow short-circuited because the hearer accesses a contextual assumption which, being very salient in the context of the conversation, somehow invalidates the on-going inferential processing, and contradicts the overall sense of the supposedly intended explicature. Two examples will illustrate my point:

First, in the film Dangerous Minds (John N. Smith 1995), one of the teachers (A) is 
looking for paper. Her strongly believed contextual assumption (21) short-circuits her optimal processing of the explicature reached in (22) and results in a what-do-you-mean question:

(21) High schools have plenty of paper for teacher use.

A. Griffith?

B. Don't let them get to you!

A. I'm not. In fact, I'm about to challenge the entire curriculum... If I could find the paper in the Xerox room...

B. You can't. There isn't any.

A. What do you mean?

B. I mean there isn't any! We're out of Xerox paper, and art paper, and we're short of pencils. But we do have plenty of students. I guess that balances things up...

A second example is taken from the film Beautiful Girls (Ted Demme 1996). In the scene quoted below, there is a group of people having a casual conversation. They are all close friends, so a strongly accessible contextual assumption such as (23) is bound to invalídate the processing of an explicature such as the one found in utterance (24), again leading to a what-do-you-mean question:

(23) All of us in this group of friends are American citizens.

(24) A. So you've been working much?

B. A few nights, you know... yeah. But... I'm actually, I'm toying with the idea of becoming a citizen.

A. What do you mean?

B. Well, I got offered this sales job. Office equipment, and it's got a pretty good base salary... plus commission. Well, I don't know. You know?

B's intended interpretation (meaning settling down like a normal, average American worker) is not reached easily once the clash between the contextual assumption (23) and the just-reached explicature in (24) is detected. This may also be studied as an ironical sense unidentified by A, in which case we would be dealing rather with a case of intended implicature turned unintended explicature (case 4 in section seven below).

One reason why this type (and also other instances) of misunderstanding arises is the fact that when we interpret utterances we are supposed to understand not only the words, but also the sense they acquire in a particular context of utterance, the 'point' of the speaker's use of words in that context, what Dascal \& Berenstein (1987) call grasping: "one often expects that the 'other' will be able to 'understand' one's 'expressive' (rather than merely 'communicative') manifestations, such as one's moods, gestures, postures of comfort or discomfort... The fallible or probabilistic nature of such expectations is often overlooked, leading to the suggestion that some form of obligation for the other to 'understand' and comply with one's wishes or needs obtains also in such cases, and this constitutes the basis for several kinds of misunderstanding" (p. 141). 
3. Cases three and four are what analysts such as Herman (1997) call misunderstanding as alternative understanding, that is, misunderstanding because an interpretation is actually chosen, but differs from the speaker's intended interpretation: "often the a-symmetries that characterize misunderstanding are the product of the very same processes that underlie understanding; misunderstanding is often an alternative understanding so that whose understanding is to count as a mis-understanding is highly contingent and context based, and not something in the abstract" (p. 33).

Specifically, in case three, after reaching the proposition expressed by the speaker's utterance through reference assignment, disambiguation, etc., a wrong selection of contextual information makes the hearer predict that the speaker wants to communicate an alternative explicature, different from the intended explicature (cf. Goodman 1986; Bazzanella \& Damiano 1999a).

For example, if there is more than one "candidate referent" to be applied to a certain word, a misunderstanding is likely to occur. This is what happens when assigning a referent to the word "paper" (here as uncountable noun) which, for instance, can refer to both "toilet paper" and "writing paper", as the following passage from Fawlty Towers illustrates ("Communication problems", BBC2, 19 February 1979):

(25) A. Hallo! girl. There's no paper in my room. Why don't you check these things? That's what you're being paid for, isn't it?

B. Well, we don't put it in the rooms.

A. What?

B. We keep it in the lounge.

A. In the lounge?!!

B. I'll get you some. Do you want plain ones or ones with our address on it?

A. Address on it?!!

B. How many sheets? How many are you going to use?

A. Manager!!

B. Just enough for one? Tell me.

A. Manager! Manager!

C. Yes? (...)

A. There you are! I've never met such insolence in all my life. I come down here to get some lavatory paper and she starts asking me the most insulting... personal... things I ever heard in my life.

B. I thought she wanted writing paper!

In this sense, indexicals such as pronouns and adverbials are very likely to be involved in misunderstandings due to a faulty or impossible assignment of the referent that they signal in the process of development of the logical form to yield the proposition expressed. There is no space here to comment upon the current scholarly discussion on the semantic or pragmatic status of indexicals (cf. Carston 1998a), but no doubt they have a clear contextual sensitivity (Bach 1998) beyond the semantic reading of the sentence, and therefore they often demand a certain amount of interpretive effort from the hearer.

To put it in a nutshell, when searching for a referent for indexicals, two main cases of incorrect understanding can be isolated. Firstly, and belonging to this case (3) of "alternative explicature", a referent for the indexical is found, but it is different from the 
intended referent. This is what happens in one of the scenes from the film In love and war (Richard Attenborough, 1996), in which two nurses (A-B) match the pronoun "he" with two different candidate referents: the doctor and a young patient (Hemingway) who has been wounded in the war:
A. Holy cow! He's good-looking.
B. Yes... but young.
A. I meant Doctor Caraccio.

Secondly, the addressee may be unable to find the intended referent of the indexical. This is precisely what happens to the pronoun "it" in the following scene from the film The mirror has two faces (Barbra Streisand, 1996):
A. I'm going to bed.
B. Mom?
A. What?
B. How did it feel?
A. How did what feel?
B. Being beautiful...
A. Being beautiful? Oh, stop it!
B. No, I mean it, how did it feel? Having people look at you with... such admiration?

The problems for reference assignment when building up an explicature also affect the location of the person or thing underlying typical referential terms such as proper names (Jaszczolt 1998: 98). There may be occasions in which the speaker is talking about someone or something and the hearer is thinking about someone or something different (and again, the hearer reaches an alternative proposition yielding a different explicature from the one intended), as is clearly exemplified in the following scene from Dangerous Minds (John N. Smith 1995):

(28) A. Who's your favourite poet, Griffith?

B. My favourite? There're so many, how do I choose?

A. I'm serious.

B. Mmm. Serious. Okay. Big "D" Dylan.

A. Get out!

B. Why not?

A. Well, I don't- He's not for everybody. I mean, he's a little long-winded, don't you think? I suppose that's because he wrote drunk.

B. He had a drinking problem?

A. The guy's Welsh, you know. There ain't a lot to do there.

B. I thought he was from Minnesota.

A. If the guy's your favourite poet, you might want to read up on him a little bit. He was Welsh, and he drank himself to death.

B. Dead? He's not dead. I saw him yesterday on MTV.

A. You saw Dylan Thomas on MTV? 


\section{B. [laughing] No! Bob Dylan! \\ A. [laughing] Bob Dylan! Oh! \\ B. He looked dead! He looked dead!}

This insight into the problems involved in finding the right referent for nouns and indexicals such as pronouns exists in the context of a growing scholarly awareness that people may not share the same referential organization when matching signs and referents in ordinary conversations, that is, may not share the same word-referent mental arrangement (i.e., a similar mapping between the interlocutors' mental and public lexicons, cf. Sperber \& Wilson 1997) and may use words and sentences in a very asymmetrical way. People constantly engage in conversations which are not totally effective because the interlocutors have different pictures of the meaning and logical implications of the words and sentences that they are using in their speaking turns. Specifically, I would underline two communicative asymmetries between interlocutors in the interpretation of explicit utterances which threaten effective communication:

(a) Interlocutors may have different pictures of when and how a certain word should be used. Words often do not have clear-cut related concepts, and the semantic attributes are often fuzzy-edged, leaving room for personal and even innovative uses of words. One of the characters in the film Beautiful Girls (Ted Demme 1996) explicitly illustrates this idea of fuzzy-edged referents for the words used by interlocutors in the course of a conversation:

(29) A. Hey! You still seeing that chick?

B. Depends on what you mean by seeing...

A. You're not engaged?

B. No, no, no.

A. Well it's been... what, a year?

B. Eleven months. Going together for eleven months, living together for six.

A. She hasn't put any pressure on you?

B. Depends on what you mean by pressure...

Thus, the so-called mapping between the public and mental lexicons varies among individuals and this may well be a source of eventual misunderstandings. The most extreme case of this asymmetry would be, of course, the personal coining of words which are incorporated into the speaker's idiolect and are often non-understood by the interlocutor. In the same film as in (29), we find a good illustration quoted in (30):

(30) A. We got, you know, a bar. A little fire place. A menu, you know? Apps...

B. Apps?

A. Yeah! Appetizers. We got apps!

B. He's the proprietor! He's got all the lingo down!

(b) Secondly, another threat to effective interpretation is the clash existing between, on the one hand, the fact that sentences may have alternative semantic readings and logical implications which can be activated without the need of a supplementive pragmatic input. For example, the sentence (31a) may logically imply either (31b) or (31c): 
(31) (a) Peter and Mary are married.

(b) Peter and Mary are married to each other.

(c) Peter and Mary are married to their respective spouses.

An aid to the hearer in determining the exact logical reading of a sentence is the fact that these readings tend to be arranged on a continuum of accessibility (that is, salience), so that (31b) is much more likely to be picked up as the logical reading of (31a) than (31c) (without denying that particular contexts may occasionally make (31c) more relevant in its accessibility). This arrangement of senses has led several analysts to follow different positions, for instance the ambiguity thesis (inherent context-free multiplicity of semantic readings) or defend a unique semantic representation that corresponds to the standard, default reading of the sentence and is achieved with the help of intentions that 'intrude' in the semantic representation (Jaszczolt 1999), among other theoretical proposals.

On the same lines as (31), to the question (32a), a logical interpretation of the answer (32b), such as (32c), is much more accessible than other alternative interpretations such as (32d-e):

(32) (a) How is your girlfriend?

(b) She's no longer my girlfriend.

(c) [They have split up].

(d) [They are now married].

(e) [His girlfriend has died].

Consequently, the misunderstanding in (33), taken from the film Four weddings and a funeral (Mike Newell 1994), is no doubt the speaker's fault, not the hearer's, since the speaker should have been aware of how salient interpretation (32c) is, compared to (32d):

(33) A. So, John, how's that, how's that gorgeous girlfriend of yours?

B. She's no longer my girlfriend.

A. Oh dear. Still, I wouldn't get too gloomy about it. Rumour has it she never stopped bonking old Toby de Lisle just in case you didn't work out.

B. She's now my wife!

A. Excellent! Excellent! Congratulations!

(...)

A. Any kids or anything, John?

Here, the speaker is unintentionally favouring the "split-up interpretation" which is much more accessible than the "now-wife interpretation" which is eventually the right one.

On the other hand, and in an opposite direction to the multiplicity or logical readings outlined above, sentences are also said to be semantically incomplete or underdeterminate (as in the required specification of referents for indexicals, for instance), so that contextual attributes are often essential for sentences to acquire an adequate sense for the purposes of the on-going conversation. Bach (1994b) illustrates cases such as (34ab) which need the incorporation of contextual support:

(a) You are not going to die. 
(b) I haven't eaten.

The truth conditions of (34a-b) are counter-intuitive:

(a) The addressee of (34a) is immortal.

(b) The utterer of (34b) has not eaten prior to the time of the utterance.

which shows how the utterer of (34a-b) will obviously expect some expansion of these utterances, such as:

(36) (a) You are not going to die [from this wound].

(b) I haven't eaten [today].

Another contextualization process involved is completion of underdeterminate sentences such as (37a-b):

(a) Steel isn't strong enough.

(b) Willie almost robbed a bank.

In (37a-b) something must be added to the sentences for them to express a complete proposition (unlike cases of expansion, which do express propositions but unsatisfactory). With (37a) we need to know [for what?] steel is strong enough, and in (37b) "what could be communicated is that Willie nearly succeeded at robbing a bank; that he decided against robbing a bank and robbed something else instead; or that he barely refrained from robbing a bank" (Bach 1994b: 269). In these cases what the conventional meaning of the sentence determines is only a fragment of a proposition - what Bach calls propositional radical - ; a complete proposition would be expressed only if the sentence were elaborated, so as to produce a completion of the proposition. ${ }^{8}$

Both characteristics of the semantic reading of sentences (multiplicity of logical readings and contextual underdeterminacy) posit further threats for optimal comprehension.

4. Returning to the diagram of the interpretive problems which can arise in the processing of explicitly communicated information, the fourth and last main source of misunderstanding is when the hearer is not satisfied with the information that the proposition expressed provides (even though the speaker intends to communicate, as an explicature, the information provided by that proposition), and then looks for extra contextual assumptions supposedly needed to reach a more relevant implicit interpretation. In other words, the hearer turns the intended explicature into an unintended implicature. There are everyday examples of this phenomenon. Harold Pinter, in his play The Dumb Waiter (1960), illustrates this speaker/hearer mismatch in the following passage, in which an explicit question concerning how many times B has read the paper is interpreted as if it were an implicit way of criticising the interlocutor (cf. Yus 1998c):

${ }^{8}$ Récanati (1993: 243) proposes a parallel terminology: saturation (whenever a slot must be contextually filled for the utterance to express a complete proposition) resembles Bach's completion; and (free) enrichment (enrichment of something more specific but which is not needed for the utterance to express a complete proposition) resembles Bach's expansion. 
(38) A. (Rising; looking down at B) How many times have you read that paper?

(B slams the paper down and rises)

B. (angrily) What do you mean?

A. I was just wondering how many times you'd...

B. What are you doing, criticizing me?

A. No, I was just...

B. You'll get a swipe round your earhole if you don't watch your step.

A. Now look here, Ben...

B. I'm not looking anywhere!

Another everyday example can be found, for example, in explicit information that the hearer unexpectedly interprets as ironical.

\section{Communication problems in the i-continuum}

Turning now to the i-continuum, four parallel sources of non-understanding and misunderstanding can be isolated (figure 2):

1. Again, there can be non-understanding due to noise in the channel, the speaker's bad pronunciation, the hearer's lack of certain encyclopaedic knowledge, etc. This is similar to case one in the previous section on the e-continuum. The recovery of both explicit and implicit interpretations of utterances requires a preliminary process of contextualization in order to access the proposition expressed. In cases of nonunderstanding in the e-continuum and the $i$-continuum, this preliminary cognitive operation is not carried out (or done unsuccessfully), and the eventual ascription of meaning to the utterance is short-circuited.

It should be noted that in this case (as in the parallel first case of the e-continuum), the hearer is often aware of not being able to build up an interpretation of the speaker's utterance. Weigand (1999: 770) further divides it into two sub-cases, a first one in which the hearer knows that s/he is not understanding and wants to be enlightened, and a second one in which the hearer knows that s/he is not understanding and wants to conceal it.

2. Secondly, and this time different from the short-circuited explicature leading to puzzled understanding which was analysed in case two above, now the hearer may not be able to reach the intended implicit implicature of the speaker's utterance due to his/her inability to access one or several contextual assumptions which are essential for the recovery of the intended implicit interpretation. One of Sperber \& Wilson's (1986a) examples is the exchange quoted in (39):
A. Is Jack a good sailor?
B. Jack is English.

In this exchange, B's indirect answer demands from A the extraction of the contextual assumption (40):

(40) The English are said to be good sailors. 
If (40) is correctly extracted from the hearer's background encyclopaedic knowledge, then the intended implicit interpretation (41) will finally be accessed.

Jack is a good sailor.

However, if the hearer is unable to access (40), a so-called missing implicature will inevitably occur, even though the hearer correctly infers that the utterance belongs to the $i$-continuum. As mentioned above, by resorting to implicitly conveyed information, the speaker relies on the hearer for the optimal outcome of interpretation and therefore is less in control of how conversation develops. This does not mean that implicit communication is not advisable. There are many reasons why people engage in this kind of communication, as I have briefly commented above. One of these is the foregrounding of assumptions such as (40) above - that are manifest for interlocutors in the course of the conversation and that become "mutually manifest" through the mediation of implicit communication (Sperber \& Wilson's 1986a; 1990 'constructed' alternative to the 'given beforehand' notion of

\section{COMMUNICATION PROBLEMS AT THE LEVEL OF IMPLICATURE}

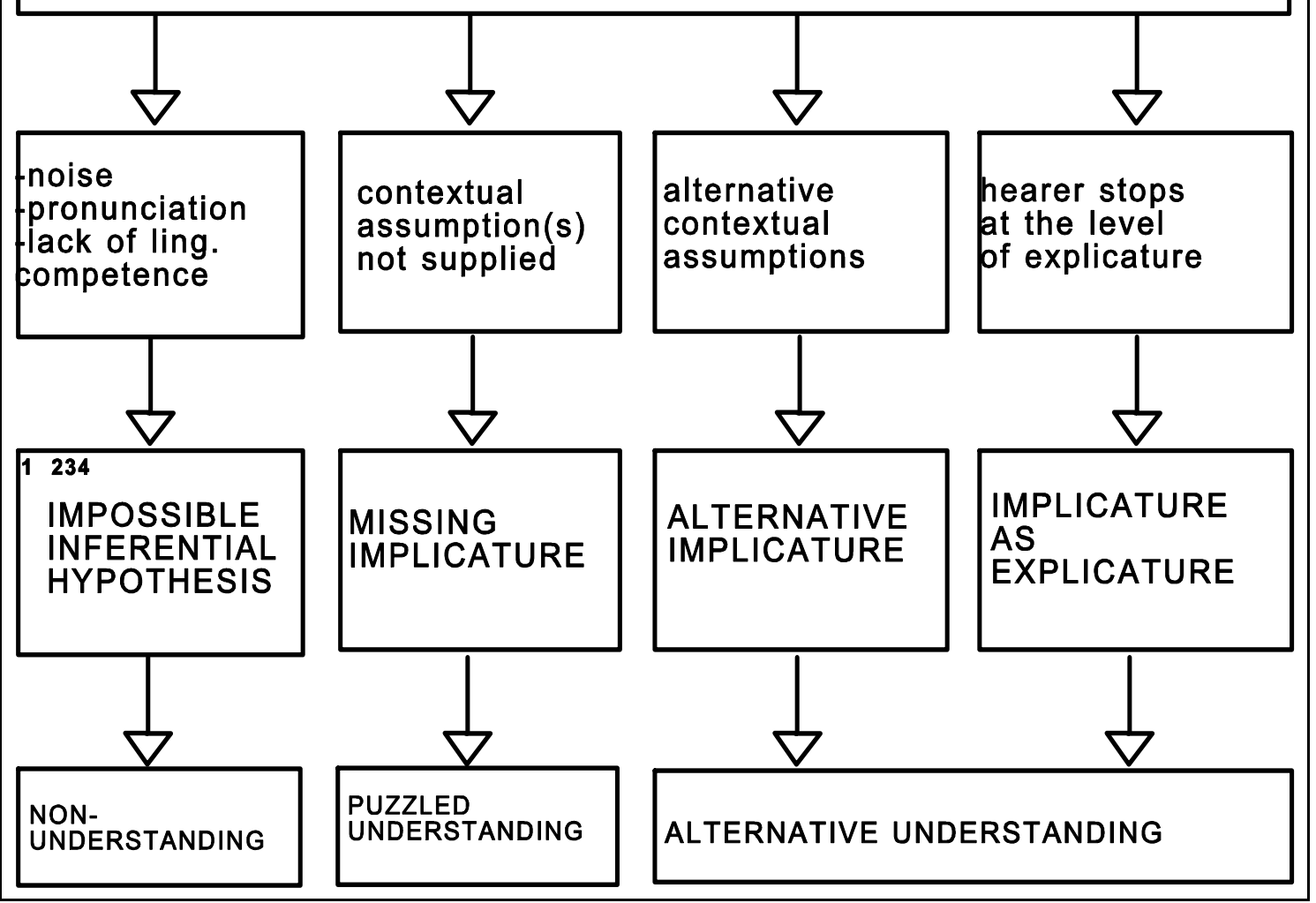

mutual knowledge; see Yus 1997a: 91-97 for discussion).

An example fitting this kind of misunderstanding took place when I engaged in the conversation quoted in (42) below, when I saw someone's cat and was unable to access the intended interpretation, because I couldn't retrieve the contextual assumption (43) from my background knowledge (in other words, the information in (43) was not mutually manifest in 
the specific cognitive environment of the conversation):

(42) A. Nice cat! Is it male or female?

B. It's three-coloured.

A. So what?

B. Never mind. It's female, actually.

All three-coloured cats are female.

Examples like this show how in implicit communication speakers have less control over the optimal outcome of interpretation since they have to rely on the interlocutors' ability to access contextual assumptions which are essential for the recovery of the intended implicit meaning.

3. Thirdly, one can select erroneous contextual assumptions leading to an alternative implicature. This is typical, for instance, of novel metaphors whose implicit meanings (often in the form of "weak implicatures") are usually the hearer's sole responsibility. For example, we can be more or less certain of what Stevie Wonder intended to communicate in his famous song containing the metaphor (44), even if we cannot be completely sure, but several weak implicatures may be proposed as hypotheses for the intended meaning of a much rarer metaphor such as (45):

(44) You are the sunshine of my life.

(45) You are the Empire State Building of my life.

As in any metaphor, in these examples a link or mapping is created between the attributes of two domains (you/sunshine, you/Empire State). The hearer is faced with a multiplicity of attributes that are candidates to fit the metaphorical mapping and may well end up suggesting an alternative implicative meaning for (44) and (45).

4. Lastly, the hearer may stop his/her interpretation of an utterance at the level of the proposition expressed, feel satisfied with the relevance that is provided (in other words, with the balance of cognitive effects and processing effort that the utterance produces in the hearer), and therefore hypothesise that the speaker intends to communicate this proposition as an explicature. In this case the hearer will not continue the search for the essential extra-contextual information required in order to access the speaker's intended implicature of the utterance. In other words, the hearer will turn the intended implicature into an unintended explicature. Typical here is, for example, interpreting an ironic utterance literally, as in (46b) below in situation (46a) (Yus 1998e: 405).

(46) a. [passengers $A$ and B sitting together on a train. After a while they strike up a conversation. A is reading a paper and makes a comment on one of the headlines]

b. A. Listen, it says here that sixty per cent of women are still unemployed in this country!

B. Yeah! Keep them in the kitchen where they belong!

A. Do you think all women should be housewives?

B. Of course not! I was only joking, for God's sake! 
In this example, the hearer is unable to recover contextual assumptions which are essential to recover the ironic sense of B's utterance, and hence opts for an explicit interpretation. As suggested in Yus (1998e), the recovery of (implicit) ironic interpretations requires the identification of some kind of incompatibility in (one or several) contextual sources, which in example (46) are not activated: "no source of incompatibility is A's accessible contextual information cen be found for B's incoming utterance. Not even A's factual knowledge about women not deserving to be kept in the kitchen is activated, because it is also a factual assumption that not everybody agrees on the role of women in society. A does not find incompatibilities in other contextual sources, not even in B's nonverbal behaviour, since B utters his statement in a default, neutral tone of voice, without any special facial gesture and with no striking sentential structure. A's misunderstanding of B's ironic utterance was predictable" (Yus 1998e: 405).

Another example of this type of misunderstanding can be seen in (47), in which a postman says "Merry Christmas" as an indirect means for asking for money, but he is understood literally (from Viz comic, in Yus 1999: 221). As a consequence, A is forced to use a nonverbal action (hold out his hand) which, following Barthes's (1977) terminology, works as an anchorage of the utterance reducing its range of possible interpretations:
[a postman $-A-$ at character $B$ 's front door]
A. A very Merry Christmas to you!!
B. Thank you. And to you.
A. [holding out his hand] Hold on! I said, Merry Christmas!
B. Oh! I see! all right. Just let me get my purse!
A. Jesus! 50p... I got a quid from next door!

\section{Concluding remarks}

In the present study, a number of cases threatening effective communication along the e-continuum and the $i$-continuum have been listed. Rather than a smooth explicit-implicit continuum in which speakers place the outcome of their interpretation, two continua have been proposed, each of them comprising different degrees of implicitness. These continua have been analysed searching for possible ways in which effective communication may turn out ineffective, and possible reasons have been suggested following a relevance-theoretic approach.

The main sources of misunderstandings in explicit/implicit communication can be summarised as follows: firstly, the hearer has to infer the explicit or implicit quality of the speaker's utterance, and also fix this ascription within the degrees of explicitness or degrees of implicitness which can be found in each continuum. This opens up a whole range of possible misunderstandings, as listed in sections six and seven above. Secondly, utterances may be ambiguous, on the one hand, and semantically underdeterminate, on the other, providing many alternative ways in which utterances can be understood, an interpretive process which runs parallel to whether the hearer correctly assigns an explicit or implicit quality to the utterance. Furthermore, the boundary between the e-continuum and the 
$i$-continuum is far from stable (even though it is supposed to be clear-cut). Rather, it is subject to a constant process of permeability favoured, among other constraints, by the evolution of culture- or speech-situation-specific communicative uses of certain utterances.

\section{References}

Bach, K. (1994a) Conversational impliciture. Mind and Language 9: 124-162.

Bach, K. (1994b) Semantic slack. What is said and more. In S.L. Tsohatzidis (ed.), Foundations of speech act theory. Philosophical and linguistic perspectives. London: Routledge, pp. 267-291.

Bach, K. (1998) Standardization revisited. In A. Kasher (ed.), Pragmatics. Critical concepts, vol. 4. London: Routledge, pp. 712-720.

Bach, K. \& R. Harnish (1979) Linguistic communication and speech acts. Cambridge, Mass.: The MIT Press (chapter 9: Indirect acts and illocutionary standardization, in A. Kasher (ed.), Pragmatics. Critical concepts, vol. 4. London: Routledge, pp. 682-712).

Barthes, R. (1977) Image-music-text. London: Fontana.

Bazzanella, C. \& R. Damiano (1999a) Coherence and misunderstanding in everyday conversations. In Bublitz and Lenk (eds.), Coherence in discourse. Amsterdam: John Benjamins Publishing Conpany, pp. $175-187$.

Bazzanella, C. \& R. Damiano (1999b) The interactional handling of misunderstanding in everyday conversations. Journal of Pragmatics 31: 817-836.

Bertolet, R. (1994) Are there indirect speech acts? In S.L. Tsohatzidis (ed.), Foundations of speech act theory. Philosophical and linguistic perspectives. London: Routledge, pp. 335-349.

Bertuccelli Papi, M. (1999) Implicitness to whom? In J. Verschueren (ed.), Pragmatics in 1998. Selected papers from the $6^{\text {th }}$ International Pragmatics Conference. Antwerp: IPrA.

Blakemore, D. (1989) Linguistic form and pragmatic interpretation: The explicit and the implicit. In L. Hickey (ed.), The pragmatics of style. London: Routledge, pp. 29-51.

Blakemore, D. (1992) Understanding utterances. Oxford: Blackwell.

Blass, R. (1990) Relevance relations in discourse. Cambridge: Cambridge University Press.

Brooks, L. (1999) Do you want to come back to my place? The Guardian, 13 December 1999, Women.

Cameron, R. \& J. Williams (1997) Senténce to ten cents: A case study of relevance and communicative success in nonnative-native speaker interactions in a medical setting. Applied Linguistics 18.4: 415-445.

Carston, R. (1988) Implicature, explicature, and truth-theoretic semantics. In R.M. Kempson (ed.), Mental representations. The interface between language and reality. Cambridge: Cambridge University Press, pp. 155-181.

Carston, R. (1996) Enrichment and loosening: Complementary processes in deriving the proposition expressed. UCL Working Papers in Linguistics 8: 61-88.

Carston, R. (1998a) The semantics/pragmatics distinction: A view from relevance theory. UCL Working Papers in Linguistics 10: 53-80. 
Carston, R. (1998b) Postcript. In A. Kasher (ed.), Pragmatics. Critical Concepts, vol. 4. London: Routledge, pp. 464-477.

Carston, R. (1999) The semantics/pragmatics distinction: A view from relevance theory. In K. Turner (ed.), The semantics/pragmatics interface from different points of view. Oxford: Elsevier Science, pp. 85-125.

Clark, H.H. (1979) Responding to indirect speech acts. Cognitive Psychology 11: 430-477.

Clark, H.H. (1996) Using language. Cambridge: Cambridge University Press.

Dascal, M. (1999) Introduction: Some questions about misunderstanding. Journal of Pragmatics 31: 753-762.

Dascal, M. \& I. Berenstein (1987) Two modes of understanding: comprehending and grasping. Language \& Communication 7: 139-151.

Dascal, M. \& O. Gruengard (1981) Unintentional action and non-action. Manuscrito IV-2: 103-113.

Díez Arroyo, M.L. (1997) Figurative vs literal meaning in idioms. A comparative study English-Spanish. Atlantis XIX(2): 51-64.

Franken, N. (1997) Vagueness and approximation in relevance theory. Journal of Pragmatics 28: $135-151$

Gibbs, R.W. (1979) Contextual effects in understanding indirect requests. Discourse Processes 2: 1-10.

Gibbs, R.W. (1984) Literal meaning and psychological theory. Cognitive Science 8: 275-304.

Gibbs, R.W. (1994) The poetics of mind. Cambridge: Cambridge University Press.

Gibbs, R.W. (1998) The varieties of intentions in interpersonal communication. In S.R. Fussell \& R.J. Kreuz (eds.), Social and cognitive approaches to interpersonal communication. Mahwah (NJ): LEA, pp. $19-37$.

Gibbs, R.W. (1999) Speaker's intuitions and pragmatic theory. Cognition 69: 355-359.

Gibbs, R.W. \& J.F. Moise (1997) Pragmatics in understanding what is said. Cognition 62: 51-74.

Goodman, B.A. (1986) Reference identification and reference identification failures. Computational Linguistics 12.4.: 273-305.

Grimshaw, A. (1980) Mishearings, misunderstandings and other nonsuccesses in talk: A plea for redress of speaker-oriented bias. Sociological Inquiry 40: 31-74.

Groefsema, M. (1992) 'Can you pass the salt?': A short-circuited implicature? Lingua 87: 103-135.

Grossen, M. (1996) Counselling and gatekeeping: Definitions of the problem and situation in a first therapeutic interview. Text 16: 161-198.

Grossen, M. \& D. Apothéloz (1996) Communicating about communication in a therapeutic interview. Journal of Language and Social Psychology 15: 101-132.

Herman, V. (1997) Misunderstanding and power: Contests of understandings. In M. Maufort \& J.-P. van Noppen (eds.), Voices of power. Brussels: Belgian Association of Anglicists in Higher Education, pp. 
$33-43$.

Holtgraves, T. (1998) Interpersonal foundations of conversational indirectness. In S.R. Fussell \& R.J. Kreuz (eds.), Social and cognitive approaches to interpersonal communication. Mahwah, NJ.: LEA, pp. 71-89.

Humphreys-Jones, C. (1986) Make, make do and mend: The role of the hearer in misunderstandings. In G. McGregor (ed.), Language for hearers. Oxford: Pergamon, pp. 105-126.

Jaszczolt, K.M. (1998) Referring in discourse: referential intention and the 'taking for granted' principle. Journal of Literary Semantics XXVII/2: 96-109.

Jaszczolt, K.M. (1999) Default semantics, pragmatics, and intentions. In K. Turner (ed.), The semantics/pragmatics interface from different points of view. Oxford: Elsevier Science, pp. 199-232.

Linell, P. (1995) Troubles with mutualities: Towards a dialogical theory of misunderstanding and miscommunication. In I. Marková, C. Graumann \& K. Foppa (eds.), Mutualities in dialogue. Cambridge: Cambridge University Press, pp. 176-213.

Maynard, D.W. (1991) On the interactional and institutional bases of asymmetry in clinical discourse. American Journal of Sociology 97: 448-495.

Nicolle, S \& B. Clark (1999) Experimental pragmatics and what is said: A response to Gibbs and Moise. Cognition 69: 337-354.

Récanati, F. (1989) The pragmatics of what is said. Mind and Language 4: 295-329.

Récanati, F. (1993) Direct reference. From language to thought. Oxford: Blackwell.

Récanati, F. (1995) The alleged priority of literal interpretation. Cognitive Science 19: 207-232.

Salazar Orvig, A. (1995) Misunderstandings and the construction of dialogue in a clinical interview. International Journal of Applied Psycholinguistics 11: 227-247.

Schegloff, E.A. (1987) Some sources of misunderstanding in talk-in-interaction. Linguistics 25: 201-218.

Schegloff, E.A. (1992) Repair after next turn: The last structurally provided defense of intersubjectivity in conversation. American Journal of Sociology 97: 1295-1345.

Searle, J.R. (1978) Literal meaning. Erkenntnis 13: 207-224.

Sperber, D. \& D. Wilson (1990) Spontaneous deduction and mutual knowledge. Behavioral and Brain Sciences 13: 179-184.

Sperber, D. \& D. Wilson (1986a) Relevance: Communication and cognition. Oxford: Blackwell.

Sperber, D. and D. Wilson (1986b) Loose talk. In S. Davis (ed.), Pragmatics: A reader. Oxford: Oxford University Press, pp. 540-549.

Sperber, D. \& D. Wilson (1987) Précis of Relevance: Communication and Cognition. Behavioral and Brain Sciences 10: 697-754.

Sperber, D. \& D. Wilson (1995) Relevance: Communication and cognition (2 ${ }^{\text {nd }}$ edition). Oxford: Blackwell.

Sperber, D. \& D. Wilson (1997) The mapping between the mental and the public lexicon. UCL Working 
Papers in Linguistics 9: 107-125.

Toolan, M. (1991) Perspectives on literal meaning. Language \& Communication 11.4: 333-351.

Vicente, B. (1996) Non-literal speech and indirection. Paper presented at the Ipra Conference. Mexico City.

Vicente, B. (1998) Against blurring the explicit/implicit distinction. Revista Alicantina de Estudios Ingleses 11 (special volume devoted to relevance theory): 241-258.

Weigand, E. (1999) Misunderstanding: The standard case. Journal of Pragmatics 31: 763-785.

Weizman, E. \& S. Blum-Kulka (1992) Ordinary misunderstanding. In M. Stamenow (ed.), Current advances in semantic theory. Amsterdam: John Benjamins Publishing Company, pp. 417-432.

Weizman, E. (1999) Building true understanding via apparent miscommunication: A case study. Journal of Pragmatics 31: 837-846.

West, C. (1985) Routine complications: Troubles with talk between doctors and patients. Bloomington: University of Indiana Press.

Wilson, D. (1994) Relevance and understanding. In: G. Brown, K. Malmkjaer, A. Pollitt \& J. Williams (eds.), Language and understanding. Oxford: Oxford University Press, pp. 35-58.

Yamaguchi, H. (1988) How to pull strings with words. Deceptive violations in the garden-path joke. Journal of Pragmatics 12: 323-337.

Yus, F. (1997a) Cooperación y relevancia. Dos aproximaciones pragmáticas a la interpretación. Alicante: Servicio de Publicaciones.

Yus, F. (1997b) Indirectness in conversation: The theory of sub-continua. Paper presented at the $X X I$ International AEDEAN Conference. Seville (Spain), December 1997.

Yus, F. (1997c) Pragmática del malentendido. Paper presented at the XV International AESLA Conference. Zaragoza (Spain), 14-16 April 1997.

Yus, F. (1997d) La teoría de la relevancia y la estrategia humorística de la incongruencia-resolución. Pragmalingüística 3-4: 497-508.

Yus, F. (1997e) La interpretación y la imagen de masas. Alicante: Instituto de Cultura "Juan Gil-Albert".

Yus, F. (1998a) A decade of relevance theory. Journal of Pragmatics 30: 305-345.

Yus, F. (1998b) Relevance: A thematic bibliographical list. Revista Alicantina de Estudios Ingleses 11 (special volume devoted to relevance theory): 261-285.

Yus, F. (1998c) The what-do-you-mean syndrome. A taxonomy of misunderstandings in Harold Pinter's plays. Estudios Ingleses de la Universidad Complutense 6: 81-100.

Yus, F. (1998d) Relevance theory and media discourse: A verbal-visual model of communication. Poetics 25: 293-309.

Yus, F. (1998e) Irony: Context accessibility and processing effort. Pragmalingüística 5-6: 391-411.

Yus, F. (1999) Towards a pragmatic taxonomy of misunderstandings. Revista Canaria de Estudios Ingleses 38: 217-239. 